\title{
The relationship between DRM and misinformation false memories
}

\author{
Bi Zhu • Chuansheng Chen • Elizabeth F. Loftus • \\ Chongde Lin • Qi Dong
}

Published online: 9 February 2013

(C) Psychonomic Society, Inc. 2013

\begin{abstract}
This research investigated the relationship between false memories induced by two different paradigms (misinformation and Deese-Roediger-McDermott [DRM]). The misinformation effect refers to the phenomenon that a person's recollection of a witnessed event can be altered after exposure to misleading information about the event. DRM false memory represents the intrusion of words that are semantically related but not actually presented in the study session. Subjects $(N=432)$ completed both misinformation and DRM false memory tests. Results showed a small but significant correlation $(r=.12, p=.02)$ between the misinformation and DRM false memories. Furthermore, using signal detection theory, we found that the discrimination ability index $\left(d^{\prime}\right)$ was related to both the misinformation and DRM false memories $(r=-.12$ and $-.13, p=.01)$, while the response bias was related only to DRM false memory $(r=-.46, p<.001)$. These results suggest that misinformation and DRM false memories generally involve different mechanisms and that their shared mechanism may involve the global discrimination ability.
\end{abstract}

Keywords False memory $\cdot$ Misinformation $\cdot$ DRM

\section{Introduction}

False memories have been extensively studied over the last three decades. In many of these studies, false memory has

Electronic supplementary material The online version of this article (doi:10.3758/s13421-013-0300-2) contains supplementary material, which is available to authorized users.

B. Zhu $\cdot$ C. Lin $\cdot$ Q. Dong $(\bowtie)$

State Key Laboratory of Cognitive Neuroscience and Learning, Beijing Normal University, Beijing, China 100875

e-mail: psydongqi@126.com

C. Chen • E. F. Loftus $(\bowtie)$

Department of Psychology and Social Behavior, University of California, Irvine, 2393 Social Ecology II, Irvine, CA 92697, USA

e-mail: eloftus@uci.edu been elicited by explicit suggestions (e.g., the misinformation paradigm [Loftus, 2003]), while in other studies, it has been elicited in the absence of explicit suggestions (e.g., the Deese-Roediger-McDermott [DRM] paradigm, [Roediger $\&$ McDermott, 1995]). The misinformation paradigm usually involves three standard stages: experiencing an event, receiving postevent misinformation, and a memory test (Loftus, 2005). These studies typically find that a person's recollection of a witnessed event can be altered after exposure to misinformation about the event (Loftus \& Hoffman, 1989). There are several interpretations of the misinformation effect. Previous studies suggested that misinformation false memories may reflect retroactive interference (e.g., people have difficulty recalling original information because of interference from the newly learned postevent information) or memory trace impairment (e.g., misinformation impairs the access to the memory trace of the original event itself [Loftus, Miller, \& Burns, 1978]). Recent brainimaging studies (Okado \& Stark, 2005; Stark, Okado, \& Loftus, 2010) have supported a third explanation-the source-monitoring hypothesis (Lindsay \& Johnson, 1989). According to this hypothesis, misinformation false memory is caused by the confusion of the sources of informationthat is, confusion between the memory of the original event and that of the postevent misinformation (Zaragoza \& Lane, 1994).

In the DRM paradigm, subjects are presented with lists of words, and each list contains words that are semantically associated with a critical lure (but the lure is not included in the list). When asked to recall the list of words they just learned, subjects frequently report having seen or heard the critical lure in the list of words studied (Roediger \& McDermott, 1995). For example, after hearing a list that includes words like tired, rest, awake, nap, and yawn, many subjects later incorrectly remember hearing the critical lure sleep. Many subjects recall or recognize that the critical lure was presented as part of the word list. The production of false memories in the DRM paradigm routinely and reliably 
occurs for adults. There are many theoretical explanations for DRM false memory (see Brainerd \& Reyna, 2005, for a review). For example, from the associative activation perspective, the processing of associated words in studied word lists activates the unstudied but semantically related critical lure. Moreover, from the thematic consistency perspective, each word list is organized around a central theme, and this thematic knowledge makes the related critical lure feel familiar. But the emergence of DRM false memory can also be explained by the feature overlap hypothesis. According to this hypothesis, the critical lure shares semantic features with the studied words, and these common features make the critical lure seem familiar or make subjects believe that they heard or saw the lure. Previous studies have shown that DRM false memory is affected by many individualdifference factors, such as suggestibility, dissociative experiences, and working memory (see Gallo, 2006, 2010, for details). Several researchers also explored the DRM false memory in special samples such as subjects with histories of child sexual abuse or posttraumatic stress disorder (Bremner, Shobe, \& Kihlstrom, 2000; Goodman et al., 2011).

There are both theoretical and practical reasons for exploring the relationship between false memories. First, such an exploration would shed light on the nature and causes of false memory (Gallo, 2010). A critical question is whether there is a common psychological mechanism underlying various types of false memories (Qin, Ogle, \& Goodman, 2008). Second, it is also of practical significance to understand the generalizability of a given false memory test such as the DRM paradigm. If there is a high level of generalizability, results from the DRM paradigm can then be used to index real-life false memories (Otgaar \& Candel, 2011). On the other hand, if there is little generalizability, results from different false memory paradigms (i.e., DRM, misinformation) cannot be used interchangeably (Otgaar \& Candel, 2011).

So, what are the relations between different types of false memories? Attempts to answer this question have produced inconsistent answers. There are even controversies about whether the different types should all be referred to as "false memories" (Pezdek \& Lam, 2007; Wade et al., 2007). On the one hand, different researchers have used different paradigms, but all labeled the construct they were measuring as false memory, suggesting their similarity. Furthermore, there is some evidence that different measures of false memories are not completely independent. For example, Clancy, McNally, Schacter, Lenzenweger, and Pitman (2002) found that people reporting recovered and repressed memories of alien abduction were more prone to false recognition (in the DRM paradigm) than were control subjects. Geraerts, Smeets, Jelicic, van Heerden, and Merckelbach (2005) found that individuals reporting recovered memories of childhood sexual abuse have more false memories (including both recall and recognition) than do other subjects in the DRM paradigm. Qin et al. (2008) found that DRM performance was associated with false childhood memory. Lövdén (2003) found a small but positive and significant correlation between DRM false recall, category-cued false recall, and false remembering of pictures. Similarly, Unsworth and Brewer (2010) explored the relation between intrusions in several different recall tasks, including the DRM test, and found positive correlations among them. Platt, Lacey, Iobst, and Finkelman (1998) reported a significant positive relationship between DRM false memory and autobiographical memory.

On the other hand, different mechanisms have also been proposed to explain different types of false memories (Wilkinson \& Hyman, 1998), although they also share common mechanisms such as source monitoring (Johnson, Hashtroudi, \& Lindsay, 1993) and the memory judgment criterion (Qin et al., 2008). For example, Salthouse and Siedlecki (2007) reported that there were no significant correlations between false recognition of words (i.e., DRM), faces, and dots. However, few of these studies included misinformation false memory.

Thus far, there is very limited research on the relationship between false memories induced by misinformation and DRM paradigms. Two studies using adults as subjects appear to present some relevant, but inconsistent, evidence. In an unpublished study (Eisen et al., 1999, cited in Eisen, Quas, \& Goodman, 2002), researchers found a modest positive relation between false recognition rates on DRM and immediate misinformation susceptibility. However, Wilkinson and Hyman (1998) revealed that the tendency to change a source judgment for an autobiographical memory (which is akin to the misinformation effect) was not related to false memories in DRM. They suggested that performance on the DRM may not be a good predictor of an individual's performance on everyday memory tasks because the two may be based on different underlying processes. Two other studies using children as subjects also appeared to present some relevant, but inconsistent, evidence. Otgaar and Candel (2011) reported that children's DRM false memory was not related to implanted false memory (i.e., planting entirely new events in memory) or interrogative suggestibility (i.e., measuring how much an interrogated person yields to leading questions or shifts their responses when additional interrogative pressure is applied), but Otgaar, Verschuere, Meijer, and Van Oorsouw (2012) reported that children's DRM false memory was related to implanted false memory in another experiment.

Moreover, the signal detection theory has been applied to recognition memory as a method of estimating internal criteria for decision making in the presence of uncertainty (Wixted, 2007). In the present study, we used recognition 
tests to examine misinformation and DRM false memories. We thought it could be profitable to explore the relations between signal detection theory variables and the two kinds of false memories. There are two common parameters used in signal detection theory (i.e., the discrimination ability index $d^{\prime}$ and response bias index $\beta$ ). Discrimination is expressed by the ability to distinguish items previously seen from those that were not seen in a prior study session, and response bias is the overall tendency to respond "old" to test items. Previous researchers found that both discrimination ability and response bias in general recognition tests were correlated with DRM false memory (Kantner \& Lindsay, 2012), while misleading information affected discrimination sensitivity more than response bias (Scoboria, Mazzoni, \& Kirsch, 2006). Therefore, to provide an integrated analysis of the entire recognition performance, we further explored the relation between discrimination ability, response bias, and two false memory indices.

The present study (1) examined false memories that were induced by two commonly used paradigms (misinformation and DRM) among a large sample of normal young adults and (2) investigated the relation between discrimination ability, response bias, and two false memory indices. Results of this study should help to clarify the relationship between two types of false memories (induced by misinformation and DRM).

\section{Method}

\section{Subjects}

The subjects were 432 undergraduates (mean age = 20 years, $S D=1 ; 55 \%$ female) who completed both the misinformation and DRM false memory paradigms. This study was approved by the IRB of Beijing Normal University, China.

False memory tests

\section{Misinformation test}

Subjects saw two events, each of which was depicted in a series of 50 digital color slides (adapted from the materials of Okado \& Stark, 2005). One event was about a man breaking into a car and stealing things from it, and the other was about a girl's wallet being stolen by a seemingly helpful man. Presentation order of the two events was randomized across subjects. Of the 50 slides making up each event, 12 critical slides were inaccurately described in the next (misinformation) stage. For each story, 50 pictures were presented in sequence, with each picture shown for 3,500 ms and with an interslide interval of $500 \mathrm{~ms}$. Next, after 30 min of filler tasks, subjects read narrations about the two events that had been previously viewed. The narratives consisted of one sentence for each slide image describing the scene depicted in the slide. For each event, 50 sentences were presented, including 12 inaccurate descriptions (misinformation) and 38 accurate descriptions (i.e., consistent with the picture slides). Each sentence was shown for $3,500 \mathrm{~ms}$, and the interval between sentences was $500 \mathrm{~ms}$. These sentences were presented in the same order as the pictures to allow for the "story" to be retold. Finally, after a 10-min filler task, subjects took the recognition test. For the recognition test, 12 critical questions (pertaining to the critical slides) were asked for each event (i.e., "you saw the picture slides and read the narrations; please try your best to answer the following questions based on what you saw in the picture slides"). We printed the words "picture slides" in red ink and highlighted them in the instructions for the recognition test. There was no explicit "warning" that narrations included misinformation. The questions were presented in random order (i.e., not following the chronology of events depicted in the slides). Each question had three possible choices as answers. Choices were a detail presented in the picture (original item), a detail presented in the narrations with misinformation (misinformation item), or a new foil detail (foil item). For example, the subjects might see in the pictures a man hiding behind a door after stealing a girl's wallet and would then read the narration that he was hiding behind a tree. For the critical question "Where was the man hiding after stealing the girl's wallet?" the choices were "behind the tree" (misinformation item), "behind the door" (original item), and "behind the car" (foil). The endorsement rates of the misinformation, original, and foil items represented the misinformation false memory (MISFM), misinformation true memory (MISTM), and misinformation foil (MISFoil), respectively. The split-half reliability for this test was .76.

\section{DRM test}

Ten word lists were used. They came from the materials used in research by Zhou (2005). Zhou adapted the word lists from those used in Roediger and McDermott (1995) to create the Chinese DRM test. Each list has 12 words that are semantically associated to a critical lure. For example, one studied list includes words such as sugar, honey, candy, cake, soda, and so on, while the unstudied critical lure was sweet. Each word was presented for $2,000 \mathrm{~ms}$, and the interword intervals were $500 \mathrm{~ms}$. After working on a filler task for about 5 min, subjects took the recognition test. They made a yes (studied) or no (unstudied) judgment for 60 words (30 studied words, 10 critical lures, and 20 unstudied unrelated 
words). The endorsement rates for the critical lures, studied words, and unstudied unrelated represented the DRM false memory (DRMFM), DRM true memory (DRMTM), and DRM foil (DRMFoil), respectively. The DRM false memory in the present study was measured by DRM false recognition. The split-half reliability for this test was .63 .

For the signal detection theory analysis, hit proportion is based on the endorsement rate for studied words in the DRM recognition test (i.e., DRMTM), and false alarm proportion is based on the endorsement rate for unstudied unrelated words in the recognition test (i.e., DRMFoil). The response bias $\beta$ was calculated as $\beta=$ $O$ (hit rate) $/ O$ (false alarm rate), and the discrimination ability index $\left(d^{\prime}\right)$ as $d^{\prime}=Z$ (hit rate) $-Z$ (false alarm rate). A higher value of $d^{\prime}$ indicates that a subject had greater ability to discriminate between studied and unstudied foil items. A higher value of $\beta$ indicates that the subject adopted a conservative bias of rejecting doubtful information as incorrect, while a lower value of $\beta$ indicates that the subject adopted a liberal bias of accepting information as correct.

All subjects took the misinformation test first and then the DRM test. These tasks were performed in a group testing setting. As part of a large project, the same group of subjects took a large number of other cognitive and personality tests, such as Raven's advanced progressive matrices and the Temperament and Character Inventory-Revised (Zhu et al., 2010a, b). These measures had been used to explore their associations with misinformation false memory (for details, see Zhu et al., 2010a, b), but they were not used in the present study.

\section{Results}

\section{Misinformation test}

Table 1 and Fig. 1 show the average endorsement rates for different items on the misinformation test. The mean rate of endorsement of the "original items" (MISTM) was $60 \%$, suggesting a high level of accuracy of memory. The mean endorsement rate for misinformation items (MISFM) was $32 \%$, and that for foil items (MISFoil) was $8 \%$. This rate of false memory inducement is consistent with previous research (Okado \& Stark, 2005). The rate for MISFM was significantly higher than that for the foil items, $t(431)=25.14, p<.001$, Cohen's $d=1.82$. There were high negative correlations between MISFM and MISTM $(r=-.93, p<.001)$ and between MISFM and MISFoil $(r=-.24, p<.001)$, but not between MISTM and MISFoil $(p>.05)$.

\section{DRM test}

The endorsement rates of different items in the DRM test are shown in Table 1 and Fig. 1. The mean accuracy for studied items was $79 \%$, indicating a high level of true memory (DRMTM). The mean endorsement rate for critical lures (DRMFM) was $66 \%$. In other words, the strong semantic connections between the presented words and the critical lures resulted in a high level of DRMFM. In comparison, the mean endorsement rate for unstudied unrelated items (DRMFoil) was only $11 \%$. This rate of false memory intrusion is consistent with previous research (Roediger \& McDermott, 1995). DRMFM was significantly higher than DRMFoil, $t(431)=58.01, p<.001$, Cohen's $d=3.04$. These results suggested that the DRM paradigm reliably created false memories. Different from the correlations among indices in the misinformation test, there were positive correlations between DRMFM and DRMTM, $r=.40, p<.001$, between DRMFM and DRMFoil, $r=.41, p<.001$, and between DRMTM and DRMFoil, $r=.31, p<.001$.

Relations between the two kinds of false memories and the signal detection theory variables

Were people who had false memories in one paradigm more likely to have them in the other paradigm? To address this issue, correlational analyses were conducted. There were statistically significant but small, positive correlations between them. The correlation coefficient between MISFM and DRMFM was .12 $(p=.02)$, and that between MISTM and DRMFM was also $-.12(p=.01) .^{1,2}$

Next, we examined the relationship between the signal detection theory variables (discrimination ability $\left[d^{\prime}\right]$ and response bias $[\beta]$ ) and the two kinds of false memory (see Table 1$)$. Discrimination ability $\left(d^{\prime}\right)$ was significantly correlated with MISFM $(r=-.12, p=.01)$, MISTM $(r=.14, p=$ 004), DRMFM $(r=-.13, p=.01)$, DRMTM $(r=.34, p<$ $.001)$, and DRMFoil $(r=-.73, p<.001)$, but $d^{\prime}$ was not significantly correlated with MISFoil $(p>.05)$. Response

\footnotetext{
${ }^{1}$ Considering the distributions of misinformation and DRM false memory scores, we transformed these distributions into normal distributions. Using these transformed scores, the correlation between two false memory scores was .12 $(p<.05)$. We also used the raw and transformed score for testing the potential linear or nonlinear relations between two false memory scores. But these results using transformed false memory scores were similar to those using the raw false memory scores. More details can be seen in the supplemental materials.

${ }^{2}$ We split the score of true memory for misinformation task by median (.625). For those people who did poorly on true memory (e.g., the lower half), the correlation between DRM and MIS false memories was not significant $(r=.06, p>.05)$. For those people who did better on true memory (e.g., the higher half), the correlation between DRM and MIS false memories was significant $(r=.17, p<.05)$. These results showed that the correlation between two false memories was larger for subjects at the higher end of the true memory scales.
} 
Table 1 Correlations among scores in the misinformation and DRM tests

\begin{tabular}{|c|c|c|c|c|c|c|c|c|c|c|}
\hline & & \multirow[b]{2}{*}{$M$} & \multirow[b]{2}{*}{$(S D)$} & \multicolumn{3}{|c|}{ Misinformation } & \multicolumn{4}{|l|}{ DRM } \\
\hline & & & & $\begin{array}{l}\text { False } \\
\text { memory }\end{array}$ & $\begin{array}{l}\text { True } \\
\text { memory }\end{array}$ & Foil & $\begin{array}{l}\text { False } \\
\text { memory }\end{array}$ & $\begin{array}{l}\text { True } \\
\text { memory }\end{array}$ & Foil & $\mathrm{SDT} d^{\prime}$ \\
\hline \multirow[t]{3}{*}{ Misinformation } & False memory & .32 & $(.18)$ & & & & & & & \\
\hline & True memory & .60 & (.17) & $-.93 * * *$ & & & & & & \\
\hline & Foil & .08 & $(.05)$ & $-.24 * * *$ & -.08 & & & & & \\
\hline \multirow[t]{5}{*}{ DRM } & False memory & .66 & $(.20)$ & $.12 *$ & $-.12 *$ & .01 & & & & \\
\hline & True memory & .79 & (.13) & -.06 & $.09 *$ & -.07 & $.40 * * *$ & & & \\
\hline & Foil & .11 & $(.16)$ & .08 & -.08 & .00 & $.41 * * *$ & $.31 * * *$ & & \\
\hline & $\mathrm{SDT} d^{\prime}$ & 2.40 & $(0.78)$ & $-.12 *$ & $.14 * *$ & -.05 & $-.13 * *$ & $.34 * * *$ & $-.73 * * *$ & \\
\hline & SDT $\beta$ & 5.90 & $(8.32)$ & -.02 & .01 & .03 & $-.46 * * *$ & $-.64 * * *$ & $-.87 * * *$ & $.37 * * *$ \\
\hline
\end{tabular}

Note. SDT $d^{\prime}$, signal detection theory variable discrimination ability; SDT $\beta$, signal detection theory variable response bias

$* p<.05$

$* * p<.01$

$* * * p<.001$

bias $(\beta)$ was significantly correlated with DRMFM $(r=-.46$, $p<.001)$, DRMTM $(r=-.64, p<.001)$, and DRMFoil $(r=$ $-.87, p<.001)$, but it was not significantly correlated with the three misinformation indices $(p>.05)$.

\section{Discussion}

The present study produced two main findings. First, both misinformation and DRM paradigms reliably created false memories, but the correlations between the two kinds of false memory were small. The correlation between misinformation and DRM false memory scores was positive and significant. Second, on the basis of the signal detection theory, discrimination ability index $\left(d^{\prime}\right)$ was negatively correlated with both the misinformation and DRM false memories, while response bias was negatively correlated only with DRM false memory.

In the misinformation paradigm, there was a high negative correlation between misinformation false memory and true memory, so they appear to reflect two different sides of the coin. Both misinformation false memory and misinformation foil are inaccurate memories, but due to the exposure of postevent misinformation, subjects were more likely to choose the misinformation items than the foils on the test. However, in the DRM paradigm, there was a moderate positive correlation between DRM false memory and true memory. It appears that the endorsement rates for the three different types of items
Fig. 1 Means and standard errors (error bars) for false memories from the misinformation test and DRM test. $* * * p<.001$

\section{Misinformation false memory}

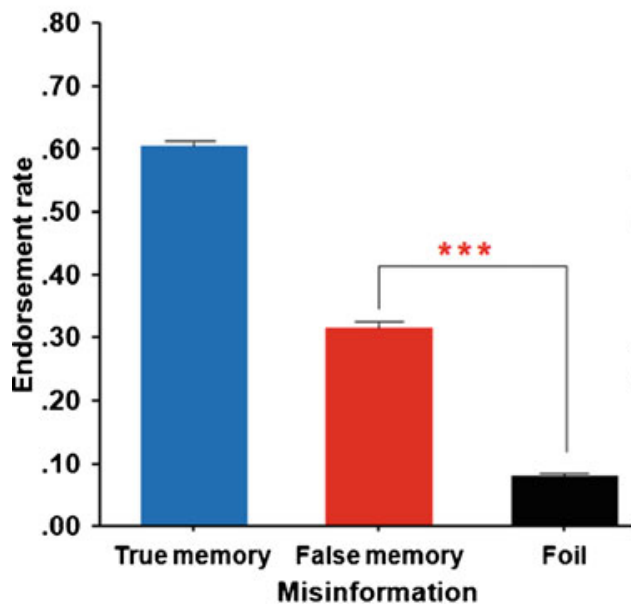

Note: $* * * p<.001$.
DRM

\section{false memory}

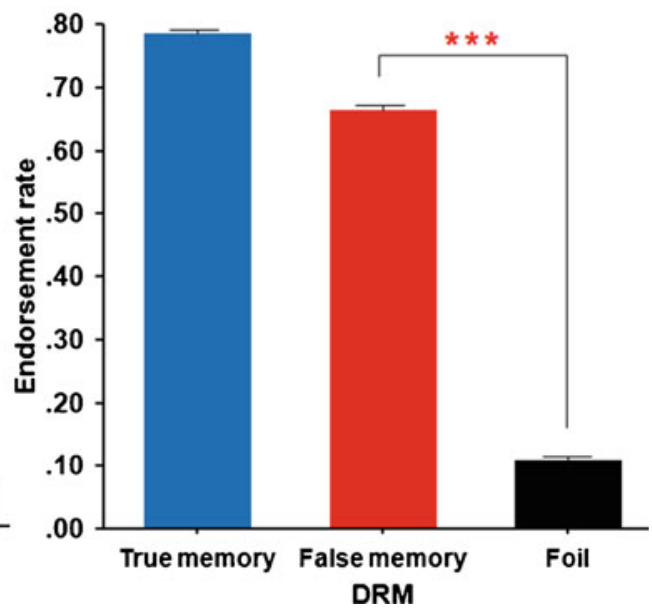


in DRM test were positively related to each other, perhaps due to semantic associations between the studied words and critical lures or due to a general judgment criterion. The two different kinds of false memory also showed dramatically different mean levels $(\mathrm{DRMFM}=.66$ and mean MISFM $=$ .32). Because these paradigms are internally consistent, the small correlation between them suggests that they may share some limited underlying mechanisms, such as discrimination ability and response bias. These results supported the idea that the two types of false memory are quite different (Liebman et al., 2002).

It is perhaps not surprising that false memories in the misinformation paradigm would involve some different mechanisms than false memories in the DRM paradigm. Previous studies have argued that different memory errors might reflect different underlying processes (Wilkinson \& Hyman, 1998). Misinformation errors involve the construction of a (wrong) memory on the basis of suggestions, whereas DRM errors do not. Misinformation errors sometimes involve acquiescence to a social demand without any real memory change. DRM errors should be less likely to arise from social demand. In the misinformation paradigm, the subjects take the external suggestion and misattribute it to their own personal memory of the original event. In the DRM paradigm, the subjects rely on the internal generation of the critical lures. In other words, the DRM paradigm may involve task- or stimulus-specific false memories, which are largely dependent on the nature of the semantic networks.

However, there are still some shared underlying mechanisms between DRM and misinformation false memories such as global discrimination ability in memory tests. We found that discrimination ability index $\left(d^{\prime}\right)$ was negatively correlated with both misinformation and DRM false memories. In other words, subjects who had high discrimination ability in the DRM recognition task were less susceptible to misinformation and less likely to recognize critical DRM words as true. Moreover, we found that response bias $(\beta)$ was negatively correlated with DRM false memory but not misinformation false memory. Our results for DRM false memory were consistent with those of Kantner and Lindsay (2012), who also found that both discrimination ability and response bias were correlated with DRM false memory. Similar to the findings of Scoboria et al. (2006), we found that misinformation false memory was correlated with discrimination sensitivity but not with response bias.

Several limitations of the present study need to be mentioned. First, we examined the relation between only two kinds of false memories. Future studies need to include other false memory paradigms. Second, we used the standard procedures for the misinformation and DRM tasks in the present study, which resulted in different formats for the recognition tests: Misinformation tasks used the forcedchoice test (with three choices of old, misinformation, and foil items), while DRM used a yes/no test. It is unknown whether this difference in test format might have lowered the correlation between these two tasks. Future studies should consider creating a three-alternative forced choice version for DRM to be compatible with the misinformation test.

To reiterate our main conclusions, using a large sample of young adults, we found that the misinformation false memory and DRM false memory scores had a small positive and significant correlation. The discrimination ability was negatively correlated with both the misinformation and DRM false memories, while the response bias was only negatively correlated with DRM false memory. These results suggest that misinformation and DRM false memories generally involve different mechanisms and that their shared mechanism may be the global discrimination ability.

Acknowledgments This study was supported by the 111 Project from the Ministry of Education of China (B07008), the National Natural Science Foundation of China (Grant 31200850), and the Specialized Research Fund for the Doctoral Program of Higher Education (20110003120002). We would like to thank Yoko Okado and Craig Stark for sharing their slides with us and for their valuable input. We are also grateful to the members from several of our labs for their valuable input to this study. Correspondence regarding this paper should be addressed to Elizabeth F. Loftus, University of California, Irvine, 2393 Social Ecology II, Irvine, CA 92697-7085 (e-mail: eloftus@uci.edu) and Qi Dong, Beijing Normal University (e-mail: psydongqi@126.com).

\section{References}

Brainerd, C. J., \& Reyna, V. F. (2005). The science of false memory. New York: Oxford University Press.

Bremner, J. D., Shobe, K. K., \& Kihlstrom, J. F. (2000). False memories in women with self-reported childhood sexual abuse: An empirical study. Psychological Science, 11(4), 333-337.

Clancy, S. A., McNally, R. J., Schacter, D. L., Lenzenweger, M. F., \& Pitman, R. K. (2002). Memory distortion in people reporting abduction by aliens. Journal of Abnormal Psychology, 111(3), 455-461.

Eisen, M. L., Lorber, W., Kistorian, R., Morgan, D., Yu, S., Tirtabudi, P., \& Cardenas, E. (1999). Individual differences in college students susceptibility to misleading information. In M. L. Eisen (Chair), Individual differences in suggestibility in memory distortion. Symposium conducted at the 3rd biennial meeting of the Society for Applied Research in Memory and Cognition, Boulder, CO.

Eisen, M., Quas, J. A., \& Goodman, G. S. (2002). Memory and suggestibility in the forensic interview. Mahwah, NJ: Lawrence Erlbaum Associates.

Gallo, D. A. (2006). Associative illusions of memory: False memory research in DRM and related tasks. New York: Psychology Press.

Gallo, D. A. (2010). False memories and fantastic beliefs: 15 years of the DRM illusion. Memory \& Cognition, 38(7), 833-848.

Geraerts, E., Smeets, E., Jelicic, M., van Heerden, J., \& Merckelbach, H. (2005). Fantasy proneness, but not self-reported trauma is 
related to DRM performance of women reporting recovered memories of childhood sexual abuse. Consciousness and Cognition, 14 (3), 602-612

Goodman, G. S., Ogle, C. M., Block, S. D., Harris, L. S., Larson, R. P., Augusti, E.-M., et al. (2011). False memory for trauma-related Deese-Roediger-McDermott lists in adolescents and adults with histories of child sexual abuse. Development and Psychopathology, 23(2), 423-438

Johnson, M. K., Hashtroudi, S., \& Lindsay, D. S. (1993). Source monitoring. Psychological Bulletin \& Review, 114, 3-28.

Kantner, J., \& Lindsay, D. S. (2012). Response bias in recognition memory as a cognitive trait. Memory \& Cognition, 40, 11631177.

Liebman, J. I., McKinley-Pace, M. J., Leonard, A. M., Sheesley, L. A., Gallant, C. L., Renkey, M. E., et al. (2002). Cognitive and psychosocial correlates of adults' eyewitness accuracy and suggestibility. Personality and Individual Differences, 33, 49-66.

Lindsay, D. S., \& Johnson, M. (1989). The eyewitness suggestibility effect and memory for source. Memory \& Cognition, 17(3), 349358.

Loftus, E. F. (2003). Make-believe memories. American Psychologist, $5,864-873$.

Loftus, E. F. (2005). Searching for the neurobiology of the misinformation effect. Learning and Memory, 12, 1-2.

Loftus, E. F., \& Hoffman, H. G. (1989). Misinformation and memory: The creation of new memories. Journal of Experimental Psychology. General, 118, 100-104.

Loftus, E. F., Miller, D. G., \& Burns, H. J. (1978). Semantic integration of verbal information into a visual memory. Journal of Experimental Psychology: Human Learning and Memory, 4, $19-31$.

Lövdén, M. (2003). The episodic memory and inhibition accounts of age-related increases in false memories: A consistency check. Journal of Memory and Language, 49, 268-283.

Okado, Y., \& Stark, C. E. L. (2005). Neural activity during encoding predicts false memories created by misinformation. Learning and Memory, 12, 3-11.

Otgaar, H., \& Candel, I. (2011). Children's false memories: Different false memory paradigms reveal different results. Psychology, Crime \& Law, 17, 513-528.

Otgaar, H., Verschuere, B., Meijer, E. H., \& Van Oorsouw, K. (2012). The origin of children's implanted false memories: Memory traces or compliance? Acta Psychologica, 139, 397-403.

Pezdek, K., \& Lam, S. (2007). What research paradigms have cognitive psychologists used to study "False memory", and what are the implications of these choices? Consciousness and Cognition, 16(1), 2-17.
Platt, R. D., Lacey, S. C., Iobst, A. D., \& Finkelman, D. (1998). Absorption, dissociation, and fantasy-proneness as predictors of memory distortion in autobiographical and laboratory-generated memories. Applied Cognitive Psychology, 12(7), 77-89.

Qin, J., Ogle, C. M., \& Goodman, G. S. (2008). Adults' memories of childhood: True and false reports. Journal of Experimental Psychology. Applied, 14(4), 373-391.

Roediger, H. L., \& McDermott, K. B. (1995). Creating false memories: Remembering words not presented in lists. Journal of Experimental Psychology: Learning, Memory, and Cognition, $21,803-814$.

Salthouse, T. A., \& Siedlecki, K. L. (2007). An individual difference analysis of false recognition. The American Journal of Psychology, 120(3), 429-458.

Scoboria, A., Mazzoni, G., \& Kirsch, I. (2006). Effects of misleading questions and hypnotic memory suggestion on memory reports: A signal-detection analysis. International Journal of Clinical and Experimental Hypnosis, 54(3), 340-359.

Stark, C. E. L., Okado, Y., \& Loftus, E. F. (2010). Imaging the reconstruction of true and false memories using sensory reactivation and the misinformation paradigms. Learning and Memory, 17, 485-488.

Unsworth, N., \& Brewer, G. A. (2010). Individual differences in false recall: A latent variable analysis. Journal of Memory and Language, 62, 19-34.

Wade, K. A., Sharman, S. J., Garry, M., Memon, A., Mazzoni, G., Merckelbach, H., et al. (2007). False claims about false memory research. Consciousness and Cognition, 16(1), 18-28.

Wilkinson, C., \& Hyman, I. E. (1998). Individual differences related to two types of memory errors: Word lists may not generalize to autobiographical memory. Applied Cognitive Psychology, 12, 29-46.

Wixted, J. T. (2007). Dual-process theory and signal detection theory of recognition memory. Psychological Review, 114(1), 152-176.

Zaragoza, M. S., \& Lane, S. M. (1994). Source misattributions and the suggestibility of eyewitness memory. Journal of Experimental Psychology: Learning, Memory, and Cognition, 20, 934-945.

Zhou, C. (2005). False memory: theories and experiments. Unpublished doctoral dissertation. East China Normal University, China.

Zhu, B., Chen, C., Loftus, E. F., Lin, C., He, Q., Chen, C., et al. (2010a). Individual differences in false memories from misinformation: Cognitive factors. Memory, 18, 543-555.

Zhu, B., Chen, C., Loftus, E. F., Lin, C., He, Q., Chen, C., et al. (2010b). Individual differences in false memory from misinformation: Personality characteristics and their interactions with cognitive abilities. Personality and Individual Differences, 48, 889-894 